\title{
High prevalence of antibiotic resistance in commensal Escherichia coli among children in rural Vietnam
}

Oliver James Dyar ${ }^{1 \dagger}$, Nguyen Quynh Hoa ${ }^{2,3^{*}{ }^{+}}$, Nguyen V Trung ${ }^{4}$, Ho D Phuc ${ }^{5}$, Mattias Larsson ${ }^{1,6}$, Nguyen TK Chuc ${ }^{2}$ and Cecilia Stålsby Lundborg ${ }^{1}$

\begin{abstract}
Background: Commensal bacteria represent an important reservoir of antibiotic resistance genes. Few communitybased studies of antibiotic resistance in commensal bacteria have been conducted in Southeast Asia. We investigated the prevalence of resistance in commensal Escherichia coli in preschool children in rural Vietnam, and factors associated with carriage of resistant bacteria.

Methods: We tested isolates of E. coli from faecal samples of 818 children aged 6-60 months living in FilaBavi, a demographic surveillance site near Hanoi. Daily antibiotic use data was collected for participating children for three weeks prior to sampling and analysed with socioeconomic and demographic characteristics extracted from FilaBavi's re-census survey 2007. Descriptive statistics were generated, and a logistic regression model was used to identify contributions of the examined factors.

Results: High prevalences of resistance were found to tetracycline (74\%), co-trimoxazole (68\%), ampicillin (65\%), chloramphenicol (40\%), and nalidixic acid (27\%). Two isolates were resistant to ciprofloxacin. Sixty percent of isolates were resistant to three or more antibiotics. Recent sulphonamide use was associated with co-trimoxazole resistance [OR 3.2, 95\% Cl 1.8-5.7], and beta-lactam use with ampicillin resistance [OR 1.8, 95\% Cl 1.3-2.4]. Isolates from children aged 6-23 months were more likely to be resistant to ampicillin [OR 1.8, 95\% Cl 1.3-2.4] and cotrimoxazole [OR 1.5, 95\% Cl 1.1-2.0]. Associations were identified between geographical areas and tetracycline and ampicillin resistance.

Conclusions: We present high prevalence of carriage of commensal E. coli resistant to commonly used antibiotics. The identified associations with recent antibiotic use, age, and geographical location might contribute to our understanding of carriage of antibiotic resistant commensal bacteria.
\end{abstract}

\section{Background}

The growing problems posed by antibiotic resistance continue to be recognised and reported on [1-4]. Rising antibiotic resistance leads to increased mortality and morbidity, enhanced transmission of resistant bacteria, and increased health costs [2]. The European Centre for Disease Prevention and Control estimates that antibiotic resistance caused at least 25,000 deaths in Europe in 2007, which was over half the annual number of deaths

\footnotetext{
* Correspondence: quynhhoa29@gmail.com

† Contributed equally

${ }^{2}$ Health System Research, Hanoi Medical University, 1 Ton That Tung street, Hanoi, Vietnam

Full list of author information is available at the end of the article
}

caused by road traffic incidents in the same countries [5].

The mechanisms that produce antibiotic resistance are coded for in genes, which may be located on bacterial chromosomes or on mobile elements that may pass between different bacteria, such as plasmids [6]. An important reservoir of antibiotic resistance genes is found in commensal bacteria, which are further capable of facilitating the spread of such genes to pathogenic strains of bacteria $[7,8]$. The largest population of commensal bacteria is that found in the gut, where they are at risk of exposure to orally ingested antibiotics, as well as certain parenteral preparations [9].

\section{Biomed Central}

(c) 2012 Dyar et al; licensee BioMed Central Ltd. This is an Open Access article distributed under the terms of the Creative Commons Attribution License (http://creativecommons.org/licenses/by/2.0), which permits unrestricted use, distribution, and reproduction in any medium, provided the original work is properly cited. 
Most studies describing the distribution of resistant bacteria have used clinical pathogens or commensal bacteria from people in healthcare settings. Data on resistance in commensal bacteria isolated from community settings have been reported on less frequently, especially so from Southeast Asia, where the findings have consistently shown high prevalences of resistance [9-12].

The most important determinant of the emergence of bacterial antibiotic resistance, both in individuals and populations, is antibiotic use [13]. In community settings young children tend to be the most exposed to antibiotics, and several studies have found that younger children have the highest risk of carrying resistant commensal bacteria [11,14]. Escherichia coli, a near ubiquitous coloniser of the gastrointestinal tract in children and adults, has often been used in studies of resistance in commensal bacteria [11,15-17]. E. coli has been shown to develop resistance in response to antibiotic use, and to be particularly capable of exchanging antibiotic resistance genes with pathogenic bacteria $[7,18]$. Recently, a number of other factors associated with carriage of resistant commensal organisms have been reported, but the various contributions of these remains unclear $[15,16]$.

The aim of our study was to investigate the prevalence of resistance to antibiotics in commensal $E$. coli carried by preschool children in the population of a rural area of North Vietnam, and to further examine whether antibiotic use and a number of demographic and socioeconomic variables were associated with carriage of resistant $E$. coli. This study is part of a larger project conducted in a rural area in northern Vietnam where data have been collected on perceptions of child caregivers regarding antibiotic use [19], knowledge and practice of healthcare providers [20], prevalence of antibiotic resistance in Streptococcus pneumoniae [21] and reported antibiotic use [22].

\section{Materials and methods Study area}

The study was carried out in Bavi district, $60 \mathrm{~km}$ west of Hanoi, Vietnam. The population of the region is approximately 250,000 persons, living in lowland, highland and mountainous areas. Children under five years of age account for $8 \%$ of the population. The public health care system consists of a 150 bed district hospital, 3 regional polyclinics and 32 commune health stations. There are also more than 200 private providers in the region, including private clinics, private pharmacies and traditional healers. The FilaBavi Epidemiological Field Laboratory was established in Bavi in 1998 [23]. Baseline and re-census surveys have been carried out every second year, with follow-up of vital events conducted every three months. FilaBavi is divided into units, referred to as clusters, with around 600-700 inhabitants in each cluster. In total there are 69 clusters within FilaBavi, including around 51,000 inhabitants and 12,000 households.

\section{Subjects and sample size}

A sufficient number of clusters were included from each geographical area (lowland, highland, mountainous) to reach the total calculated sample size. This calculation was based on the finding from a previous study that $70 \%$ of children under five in the community used antibiotics during one month [24], with an expected drop out of $30 \%$, and a design effect of 2.0 due to clustering. All of the households in the largest clusters within each geographical area were selected to include about 280 households in each area. Between March and June 2007 a total sample of 847 children was selected from 847 households in which at least one child was eligible for the study. One child aged 6-60 months at the time of study was randomly selected within each household that had more than one child fulfilling the inclusion criteria, using a computer. Data were extracted from FilaBavi's re-census survey 2007 on the participants' characteristics, date of birth, sex, residential areas, parents' education and households' assets, expenditure and income.

\section{Survey of drug use and sampling of isolates}

Interviews with structured questionnaires were conducted weekly with the main child-caregiver in the household in order to collect information on reported daily illness symptoms and drug use for the participating child over a four-week period. Caregivers were requested to complete a form detailing daily drug use for the child. If available, the prescription or drug package was checked by the interviewers. Drugs used were classified according to the Anatomical Therapeutic Chemical (ATC) classification system [25] with the assistance of VN-pharmacy software [26]. This study includes only antibiotics classified as antibacterials for systemic use. These are aggregated at the level of the active ingredient (level 5 of the ATC class J01) [25].

Children were invited to attend the health commune station for a clinical examination on the 21st day of participation in the study. This was conducted by paediatricians from district or central hospitals. Faecal samples were collected by trained microbiologists, and immediately placed in a Cary-Blair transport tube. Within $12 \mathrm{~h}$ of sampling, all specimens reached the Clinical Laboratories of the National Institute of Infectious and Tropical Diseases, Hanoi.

E. coli was isolated and identified using standard laboratory procedures [27]. Briefly, presumptive E. coli isolates were picked based on typical colony morphology and Gram staining. Identification was confirmed by API 
20E strip test (bioMérieux, France). E. coli serotyping was conducted following a protocol previously described [28], with the minor modification that the multiplex PCR assay was carried out on DNA extracted from a smear of bacteria from the first area of a MacConkey plate. Separate to this, a single colony was selected and sub-cultured for purity check and antibacterial susceptibility testing. The serotyping was conducted using a smear of colonies, whereas the antibiotic susceptibility testing used a single colony. Therefore it cannot be assumed that where diarrhoeagenic strains were found to be carried by a child that it was a colony of the same strain that also underwent susceptibility testing.

\section{Antibacterial susceptibility testing}

For all isolates, inhibitory zone diameters were measured for tetracycline, co-trimoxazole, ampicillin, chloramphenicol and nalidixic acid using disk diffusion (BIO-RAD Laboratories, Marnes-la-Coquette, France). Minimum inhibitory concentrations were determined for ciprofloxacin using Etest (AB bioMérieux, Solna, Sweden, formerly $\mathrm{AB}$ BIODISK) for all isolates except for nine that did not survive storage. The antibiotics tested were those recommended for testing by the Clinical and Laboratory Standards Institute (CLSI) [29]. Susceptibility testing was carried out according to the performance standards of CLSI and the technical instructions of manufacturers. E. coli ATCC 25922 was used as the control strain in susceptibility tests. Testing conditions and reading of the diameter of the inhibitory zones and the MICs followed CLSI guidelines.

Interpretative breakpoints were based on the 2010 CLSI standards for this paper [30]. Susceptible or intermediately susceptible isolates were categorized as susceptible. Decreased susceptibility of isolates to the tested antibiotics was also determined using the epidemiological cut-off values (ECOFF) defined by the European Committee on Antimicrobial Susceptibility Testing (EUCAST) [31].

\section{Statistical analysis}

Frequencies and proportions of isolates resistant to the tested antibiotics were calculated. A two stage process was used to determine associations with the outcome measures of (i) resistance to any antibiotic, and (ii) resistance to a specific antibiotic. The variables were first tested for association in univariate analysis using chi-square test, with those approaching statistical significance then entered into the binomial logistic regression model with backward selection. The independent variables assessed were: sex (male vs. female), age (6-23 months vs. 24-60 months), presence of diarrhoea (yes vs. no), economic status of the household (average or above vs. below average), number of children aged 0-17 living in household (one vs. more than one), area (lowland, highland vs. mountains), reported antibiotic use of any antibiotic class within the three weeks preceding the sample collection day (yes/no) and use of a specific class of antibiotic within the three weeks preceding the sample collection day (J01C, J01D, J01E, J01F). All statistical analyses were conducted using PASW Statistics 18.0 (SPSS Inc., Chicago, IL, USA), with a significance level of $\mathrm{p}=0.05$.

\section{Ethical considerations}

Approval for the study was received from the ethical review board of Hanoi Medical University (No 28/ HMURB, 2006). Permission for the study and use of census data was received from the FilaBavi steering committee. All parents were asked for verbal consent after explanation of the purpose and methods of the study. Confidentiality was assured, and participants were made aware of their right to withdraw at any time in the study period without explanation. Children identified at clinical examination as having need of medical care were treated and counselled by the paediatricians from the district or central hospitals.

\section{Results}

\section{Study population}

Of the 847 selected children, 818 (99\%) caregivers consented for their child to participate in the clinical examination and collection of faecal samples. The characteristics of the children are shown in Table 1.

\section{E. coli serotypes}

All 818 samples were analysed to detect the E. coli serotypes present. Non-diarrhoeagenic $E$. coli were found in 738 (90\%) isolates. The most common diarrhoeagenic subtype was enterohaemorrhagic E. coli (EHEC), identified in $42(5 \%)$ samples. Enteroaggregative E. coli was found in 28 (3\%) samples, enterotoxigenic E. Coli in 26 (3\%) samples, enteropathogenic E. coli in 12 (1\%) samples, and enteroinvasive E. coli in one sample.

\section{Resistance to single and multiple antibiotics}

Only 46 isolates (6\%) were sensitive to all antibiotics tested. Prevalences of resistance to single and multiple antibiotics are presented in Table 2. The distribution of zone diameter and MIC values are shown in Figure 1. Resistance to multiple antibiotics was very common, with $60 \%$ isolates resistant to three or more antibiotics tested. The modal value was resistance to four antibiotics. The most common patterns of resistance to multiple drugs were to tetracycline and co-trimoxazole (57\% isolates), to co-trimoxazole and ampicillin (54\% isolates), and to tetracycline and ampicillin (53\% isolates). Combined resistance to tetracycline, co-trimoxazole, ampicillin and chloramphenicol was found in $25 \%$ isolates. 
Table 1 Selected sociodemographic characteristics of participating rural children aged 6-60 months from FilaBavi, Vietnam

\begin{tabular}{|c|c|c|}
\hline \multicolumn{2}{|l|}{ Characteristics } & \multirow{2}{*}{$\begin{array}{c}\begin{array}{c}\text { Participating children } \mathbf{n}= \\
\mathbf{8 1 8}(\%)\end{array} \\
373(46)\end{array}$} \\
\hline Sex & Female & \\
\hline & Male & $445(54)$ \\
\hline \multirow[t]{2}{*}{ Age } & 6-23 months & $367(45)$ \\
\hline & $\begin{array}{l}24-60 \\
\text { months }\end{array}$ & $451(55)$ \\
\hline \multirow[t]{3}{*}{ Geographical area } & Lowland & $268(33)$ \\
\hline & Highland & $275(34)$ \\
\hline & Mountains & $275(34)$ \\
\hline \multirow[t]{2}{*}{$\begin{array}{l}\text { Household economic } \\
\text { status }\end{array}$} & $\begin{array}{l}\text { Below } \\
\text { average }\end{array}$ & $337(46)$ \\
\hline & $\begin{array}{l}\text { Average or } \\
\text { above }\end{array}$ & $441(54)$ \\
\hline \multirow{2}{*}{$\begin{array}{l}\text { Number of children in } \\
\text { household }\end{array}$} & One & $219(27)$ \\
\hline & $\begin{array}{l}\text { More than } \\
\text { one }\end{array}$ & $599(73)$ \\
\hline \multirow[t]{2}{*}{ Diarrhoea } & Present & $10(01)$ \\
\hline & Not present & $808(99)$ \\
\hline \multirow{2}{*}{$\begin{array}{l}\text { Reported antibiotic use } \\
\text { in } 21 \text { days } \\
\text { before sampling }\end{array}$} & Yes & $477(58)$ \\
\hline & No & $341(42)$ \\
\hline
\end{tabular}

\section{Determinants of resistance}

Binomial logistic regression models were used to identify demographic, socioeconomic, and antibiotic use associations with resistance to any antibiotics tested, and to individual antibiotics (with the exception of ciprofloxacin due to the low number of isolates with ciprofloxacin resistance). Comparison prevalences for selected variables are shown in Table 3. Isolates taken from children aged 6-23 months were associated with resistance to ampicillin [OR 1.8, 95\% CI 1.3-2.4], co-trimoxazole [OR 1.5, 95\% CI 1.1-2.0], and chloramphenicol [OR 1.3, 95\% CI 1.0-1.8]. Isolates from children living in the lowland area were less likely to be resistant to tetracycline [OR 0.62, 95\% CI 0.42-0.90]. No association was found between antibiotic resistance and socioeconomic class, number of children living in the household, or presence of diarrhoea symptoms at time of sampling.

Analysis of antibiotic use in the logistic regression models was restricted to the antibiotics most commonly used during the study period, beta-lactams, sulphonamides and antibiotics of the J01F class. Children that had taken sulphonamides were more likely to carry $E$. coli resistant to co-trimoxazole [OR 3.2, 95\% CI 1.8-5.7], and resistant to nalidixic acid [OR 1.8, 95\% CI 1.2-2.8]. Prior use of beta-lactam antibiotics was associated with carriage of E. coli resistant to any antibiotic tested [OR 2.3, 95\% CI 1.3-4.0], resistant to ampicillin [OR 1.8, 95\%
Table 2 Resistance prevalence to tested antibiotics among 818 isolates of E.coli from children aged 6-60 months in FilaBavi, Vietnam

\begin{tabular}{cc}
\hline Antibiotic(s) tested & $\begin{array}{c}\text { Prevalence of resistance \% ( } \mathbf{n} \text {, total } \mathbf{n} \\
\mathbf{8} 818)\end{array}$ \\
\hline TET & $74(609)$ \\
SXT & $68(559)$ \\
AMP & $65(533)$ \\
CHL & $40(325)$ \\
NAL & $27(220)$ \\
CIP & $<1(2)$ \\
TET + SXT & $57(468)$ \\
TET + AMP & $52(424)$ \\
TET + CHL & $34(275)$ \\
TET + NAL & $20(164)$ \\
SXT + AMP & $54(441)$ \\
SXT + CHL & $34(277)$ \\
SXT + NAL & $23(185)$ \\
AMP + CHL & $33(270)$ \\
AMP + NAL & $18(151)$ \\
CHL + NAL & $13(109)$ \\
TET + SXT + AMP & $45(368)$ \\
TET + SXT + AMP + CHL & $25(208)$ \\
TET + SXT + AMP + CHL + & $8(68)$ \\
NAL &
\end{tabular}

Abbreviations used: TET = tetracycline; SXT = co-trimoxazole; $\mathrm{AMP}=$ ampicillin; $\mathrm{CHL}=$ chloramphenicol; $\mathrm{NAL}=$ nalidixic acid; $\mathrm{CIP}=$ ciprofloxacin ' + ' indicates 'and'

The results presented are based on data interpreted using CLSI clinical breakpoints

CI 1.3-2.4], and resistant to chloramphenicol [OR 1.3, 95\% CI 1.0-1.8]. Children that had taken antibiotics of the J01F class (macrolides, lincosamides and streptogramins) were more likely to carry $E$. coli that tested resistant to ampicillin [OR 2.1, 95\% CI 1.1-4.1] and nalidixic acid [OR 1.7, 95\% CI 1.0-3.0]. Children that used sulphonamides in the seven days prior to sampling only, or between eight and twenty-one days prior to sampling, had significantly higher carriage of $E$. coli isolates resistant to co-trimoxazole than children that did not take any sulphonamides during the study period (95\% and $86 \%$ vs. $66 \%$ ). Similarly, children that used beta-lactams exclusively in the seven days prior to sampling, or between eight and twenty-one days prior to sampling, were significantly more likely to carry isolates resistant to ampicillin (74\% and $70 \%$ vs. $58 \%)$.

\section{Epidemiological cut-off analysis}

For each antibiotic tested, zone diameters or MIC values were analysed using EUCAST epidemiological cut-off (ECOFF) values, in addition to using the clinical CLSI criteria. The ECOFF values identify bacteria that exhibit reduced susceptibility to antibiotics as compared with the wildtype population. Decreased susceptibility, 


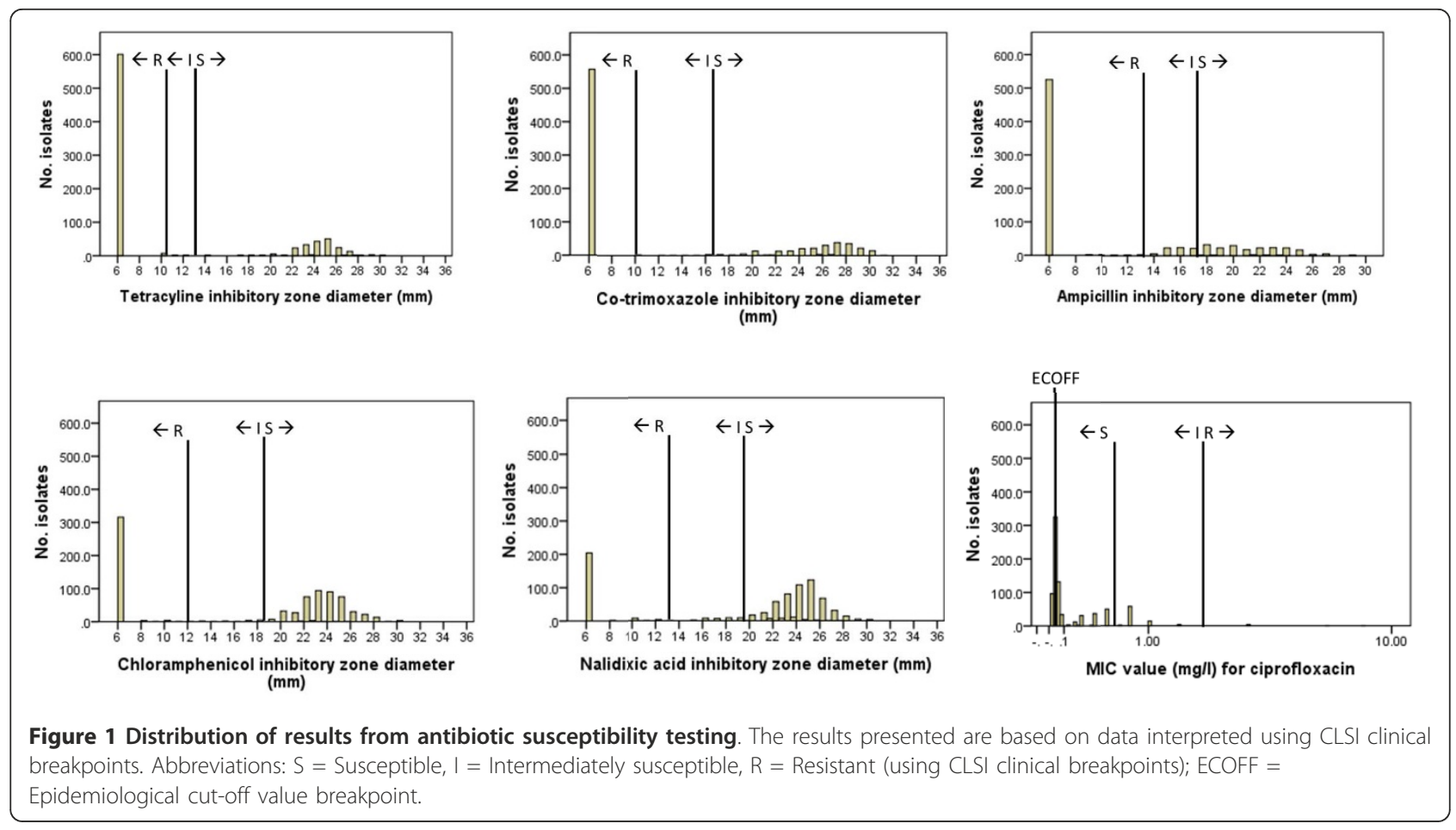

according to ECOFF values, was found to tetracycline in $614(75 \%)$ isolates, to ciprofloxacin in 605 (74\%) isolates, to co-trimoxazole in $563(69 \%)$ isolates, to ampicillin in $533(65 \%)$ isolates, to chloramphenicol in 332 (41\%)

Table 3 Summary of resistance prevalence according to sociodemographic factors and antibiotic use among 818 isolates of E.coli from children aged 6-60 months in FilaBavi, Vietnam

\begin{tabular}{lccccccc}
\hline & \multicolumn{7}{c}{ Prevalence of resistance \% } \\
& AMP & SXT & TET & CHL & NAL & CIP \\
\hline Age & $73^{*}$ & $73^{*}$ & 76 & $46^{*}$ & 30 & 0.3 \\
$\begin{array}{l}6-23 \text { months } \\
24-60 \text { months } \S\end{array}$ & 59 & 64 & 74 & 37 & 24 & 0.2 \\
Household economic status & & & & & & \\
$\begin{array}{l}\text { Below average } \\
\text { Average and above } \S\end{array}$ & 67 & 68 & 78 & 40 & 24 & 0.3 \\
Geographical area & 64 & 68 & 72 & 41 & 29 & 0.2 \\
Lowland & & & & & & \\
Highland & 60 & 66 & $68^{*}$ & 41 & 30 & 0.0 \\
$\begin{array}{l}\text { Mountains } \S \\
\text { Any reported antibiotic use in } \\
\text { prior 21 days }\end{array}$ & 73 & 67 & 78 & 43 & 27 & 0.4 \\
No & 62 & 72 & 78 & 39 & 23 & 0.4 \\
Yes & & & & & & \\
\hline
\end{tabular}

*Result was statistically significant using binomial logistic regression §Reference group used in binomial logistic regression

Abbreviations used: TET = tetracycline; $\mathrm{SXT}=$ co-trimoxazole; $\mathrm{AMP}=$ ampicillin; $\mathrm{CHL}=$ chloramphenicol; NAL = nalidixic acid; $\mathrm{CIP}=$ ciprofloxacin

The results presented are based on data interpreted using CLSI clinical breakpoints isolates, to nalidixic acid in 246 (30\%) isolates. Eleven isolates $(1.3 \%)$ showed wildtype susceptibility to all tested antibiotics. The MIC values for ciprofloxacin susceptibility testing are shown along with the ECOFF and CLSI clinical breakpoints for ciprofloxacin in Figure 1.

\section{Discussion}

This is the first community-based study in Vietnam to explore the prevalence of antibiotic resistance and their determinants in commensal E. coli. It increases the limited knowledge of the prevalence of resistance to different antibiotics that are found in a rural population in a lower middle income country. A study of 113 children from rural areas around Hanoi conducted between 1996-1999 found similar resistance prevalences for cotrimoxazole, ampicillin and ciprofloxacin [10]. Comparisons between these studies are limited by differences in methodologies (we used CLSI interpretative breakpoints, whereas the authors in the previous study followed standards set by the Swedish Reference Group for antibiotics), and that the majority of children in this previous study had diarrhoea, whereas most children in our study did not ( $95 \%$ vs. $1 \%$ presence of diarrhoea).

A more recently published study in urban Hanoi examined resistance exclusively in diarrhoeagenic serotypes of $E$. coli in a mixture of children with diarrhoea in hospital and healthy children from daycare and healthcare centres, with no differences found in resistance prevalences between the two groups [32]. Compared with our study, that study reported higher 
prevalences of resistance to co-trimoxazole $(89 \%$ vs. $68 \%$ ), ampicillin (86\% vs. $65 \%$ ), chloramphenicol $(77 \%$ vs. $40 \%)$, and ciprofloxacin ( $4 \%$ vs. $<1 \%$ ), but a lower prevalence of resistance to nalidixic acid (19\% vs. $27 \%$ ). These differences may reflect higher levels of access and use of antibiotics in the urban setting. The prevalences identified in children in FilaBavi are considerably higher for most antibiotics than the few reported rural community studies in other areas of Southeast Asia, including Thailand and Indonesia [10,11]. Reports from community studies in rural areas in India and Peru have also presented lower prevalences of resistance in commensal E. coli than identified here $[15,16]$.

Compared with children aged 24-60 months, isolates taken from children aged 6-23 months had higher prevalences of resistance to co-trimoxazole, ampicillin and chloramphenicol. This is in keeping with a few previous reports which have suggested that age can act as a risk factor for carriage of resistant bacteria, independent of increased antibiotic use of younger children [13,33]. The higher prevalence of ampicillin resistance in the highland area may be partly explained by a higher proportion of children taking beta lactam antibiotics in this area than in the other areas. Living in the lowland areas was independently associated with isolates having a lower prevalence of tetracycline resistance, a drug which should not be administered to children. This may reflect previously lower use of tetracyclines within the lowland area, or differences in exposure of E. coli to tetracylines from other sources, such as agriculture.

The majority of antibiotic use in our study was for the treatment of acute respiratory tract illnesses [22]. Analysis of specific antibiotic use showed that the antibiotics most commonly taken by the children, beta-lactams and sulphonamides, were strong risk factors for carriage of ampicillin and co-trimoxazole resistant isolates, respectively. This highlights the importance of individual antibiotic use in selecting for carriage of resistant E. coli. Some studies have failed to find associations between antibiotic use and resistance in commensals in community settings, which may reflect important differences in methodologies employed, such as not analysing by use of specific antibiotic classes $[16,34,35]$. Our data show a trend towards higher prevalence of co-trimoxazole and ampicillin resistance in isolates from children who took sulphonamide and beta-lactam antibiotics, respectively, in the seven days prior to sampling, compared with children who only took these antibiotics between eight and twenty-one days prior to sampling. Both of these subgroups remained significantly higher than children unexposed to these antibiotics during the study period.

CLSI criteria are used to identify bacteria that demonstrate resistance to antibiotics in a clinical setting, whereas ECOFF values are designed to identify bacteria that show reduced susceptibility to an antibiotic, as compared with the wildtype population of bacteria. Analysis of decreased susceptibility according to EUCAST ECOFF values produced comparable results for most antibiotics to those reached through the use of the CLSI clinical breakpoints. This reflects the similarity in the CLSI clinical breakpoint values and the EUCAST ECOFF values for $E$. coli. However, a considerable difference was observed for ciprofloxacin. Whereas $0.2 \%$ and $2.7 \%$ isolates were resistant or intermediately susceptible, respectively, using CLSI clinical breakpoints, $74 \%$ of isolates were found to have decreased susceptibility compared with the wildtype population, according to EUCAST ECOFF value. As few studies have thus far presented comparisons between the prevalence of decreased susceptibility using ECOFF values and the prevalence of clinical resistance using CLSI breakpoints, interpretation of this result must be made cautiously. It is possible that this represents an emerging decrease in susceptibility of E. coli in the study area to fluoroquinolones. A study by de Jong et al. also found significant differences between clinical resistance and decreased susceptibility to ciprofloxacin in commensal E. coli isolates from healthy food-producing animals in Europe, however the magnitude of the difference was less than that found in our study [36]. The EUCAST ECOFF value for ciprofloxacin in E. coli is based on 17877 observations [37], from which a similar definition of the wildtype population was reached using a normalized resistance interpretation method [38].

We identified a prevalence of EHEC carriage of 5\%, which meant it was the dominant diarrhoeagenic E. coli subtype in our study. Two studies have found similar prevalences of EHEC carriage in asymptomatic individuals, one in workers from meat processing plants in Switzerland [39], and another in families living on dairy farms in Canada [40]. This high level of carriage might come from the large number of farm animals present in Bavi, or from other environmental sources, which we have not attempted to investigate in the present study. It may be that this high prevalence is due to a clonal spread, which could be explored in further studies. EHEC carriage was not associated with presence of any gastrointestinal symptoms, and its clinical significance remains unclear.

Our community study of resistance in commensal bacteria has several strengths, including its size and high response rate. The daily reporting of antibiotic use, validated by weekly follow up interviews, have enabled analysis of individual drug use to be correlated with antibiotic resistance, and suggested a trend towards higher resistance when antibiotics were consumed close to the date of sampling. There are also a number of limitations to our study. Importantly, only one E. coli isolate from each child was tested for antibiotic 
susceptibility, whilst it is appreciated that multiple $E$. coli strains usually co-exist in an individual's gastrointestinal tract $[17,41]$. The true prevalence of carriage of resistant $E$. coli is consequently likely to be higher than the figures presented here.

A further limitation is that the analysis on antibiotic use counted all days on which antibiotics were taken as equivalent, assuming that full doses had been taken. It has been noted elsewhere that sub-therapeutic dosing may be common in low- and middle-income countries [15]. Our study did not assess the contribution of certain potential exposures to antibiotics and antibiotic resistant bacteria remarked on elsewhere: antibiotic use by household members, day care attendance, exposure to contaminated water sources, contact with animal microflora. We have not investigated the prevalence of different mechanisms underlying the resistant phenotypes presented here.

\section{Conclusions}

Our study has identified high prevalences of resistance to individual antibiotics in commensal bacteria isolated from children in a rural area of northern Vietnam. The high prevalences of resistance seen after individual antibiotic use highlight the increasing threat posed by antibiotic resistance in Vietnam, and suggest further evidence for the need for commitment to ensuring antibiotics are used in as rational a manner as possible.

\section{Acknowledgements and funding}

The authors thank the households in FilaBavi, as well as the field surveyors, supervisors and officials of FilaBavi. We acknowledge the assistance of the staffs of the laboratories at the National Institute of Infectious and Tropical Diseases, Vietnam; the paediatricians of the National Children's Hospital, and Bavi District Hospital, Vietnam; the clinical pharmacists of Hanoi University of Pharmacy, Vietnam; and Bo Eriksson, statistician at the Nordic School of Public Health, Gothenburg, Sweden. We are grateful to AB bioMérieux's Etest plant, Solna, Sweden (formerly AB BIODISK) for the Etest donation. The work was supported by the Swedish International Development Coordination Agency, through the Ministry of Science and Technology, Vietnam (grant number 20HDNC/RF1)

\section{Author details}

${ }^{1}$ Division of Global Health (IHCAR), Department of Public Health Sciences, Karolinska Institutet, Nobels väg 9, 17177 Stockholm, Sweden. ${ }^{2}$ Health System Research, Hanoi Medical University, 1 Ton That Tung street, Hanoi, Vietnam. ${ }^{3}$ Vietnam Cuba Friendship Hospital, 37 Hai Ba Trung street, Hanoi, Vietnam. ${ }^{4}$ Department of Medical Microbiology, Hanoi Medical University, 1 Ton That Tung street, Hanoi, Vietnam. ${ }^{5}$ Department of Probability and Statistics, Institute of Mathematics, 18 Hoang Quoc Viet road, Hanoi, Vietnam. ${ }^{6}$ Oxford University Clinical Research Unit, National Hospital of Tropical Diseases, 78 Giai Phong road, Dong Da district, Hanoi, Vietnam.

\section{Authors' contributions}

OJD, NQH, NVT, HDP, ML, NTKC, CSL participated in the conception and design of the study, data interpretation and revising paper critically for substantial intellectual content. NQH was responsible for the data collection and analysed data. OJD performed data analysis and drafted the manuscript. NVT was responsible for laboratory testing. NQH, NVT, HDP, ML, NTKC, CSL supported in the data collection and contributed to draft manuscript. HDP contributed to statistical analysis. All authors read and approved the final manuscript.

\section{Competing interests}

The authors declare that they have no competing interests.

Received: 6 November 2011 Accepted: 18 April 2012

Published: 18 April 2012

\section{References}

1. Rice LB: The clinical consequences of antimicrobial resistance. Curr Opin Microbiol 2009, 12:476-481.

2. Cosgrove SE, Carmeli Y: The impact of antimicrobial resistance on health and economic outcomes. Clin Infect Dis 2003, 36:1433-1437.

3. Pitout JD, Laupland KB: Extended-spectrum beta-lactamase-producing Enterobacteriaceae: an emerging public-health concern. Lancet Infect Dis 2008, 8:159-166.

4. Rogers BA, Sidjabat HE, Paterson DL: Escherichia coli O25b-ST131: a pandemic, multiresistant, community-associated strain. J Antimicrob Chemother 2011, 66:1-14

5. The European Centre for Disease Prevention and Control: The bacterial challenge: Time to react. Stockholm 2009

6. von Baum H, Marre R: Antimicrobial resistance of Escherichia coli and therapeutic implications. Int J Med Microbiol 2005, 295:503-511.

7. Karami N, Martner A, Enne VI, Swerkersson S, Adlerberth I, Wold AE: Transfer of an ampicillin resistance gene between two Escherichia coli strains in the bowel microbiota of an infant treated with antibiotics. J Antimicrob Chemother 2007, 60:1142-1145.

8. Blake DP, Hillman K, Fenlon DR, Low JC: Transfer of antibiotic resistance between commensal and pathogenic members of the

Enterobacteriaceae under ileal conditions. J Appl Microbiol 2003, 95:428-436.

9. Alekshun MN, Levy SB: Commensals upon us. Biochem Pharmacol 2006 71:893-900.

10. Isenbarger DW, Hoge CW, Srijan A, Pitarangsi C, Vithayasai N, Bodhidatta L, Hickey KW, Cam PD: Comparative antibiotic resistance of diarrheal pathogens from Vietnam and Thailand, 1996-1999. Emerg Infect Dis 2002, 8:175-180

11. Duerink DO, Lestari ES, Hadi U, Nagelkerke NJ, Severin JA, Verbrugh HA, Keuter M, Gyssens IC, van den Broek PJ: Study Group Antimicrobial Resistance in Indonesia: Prevalence and Prevention (AMRIN): Determinants of carriage of resistant Escherichia coli in the Indonesian population inside and outside hospitals. J Antimicrob Chemother 2007, 60:377-384.

12. Ha Nguyen Thanh Thi Thi, Long Hoang Thuy, Nguyen Hoi Thi: The Tram Nguyen, Lundström G, Olsson-Liljequist B, Kallings I: Antibiotic sensitivity of enteric pathogens in Vietnam. Int J Antimicrob Agents 1991, 1:121-126.

13. Bronzwaer SL, Cars O, Buchholz U, Mölstad S, Goettsch W, Veldhuijzen IK, Kool JL, Sprenger MJ, Degener JE: European Antimicrobial Resistance Surveillance System: A European study on the relationship between antimicrobial use and antimicrobial resistance. Emerg Infect Dis 2002, 8:278-282

14. Okeke IN, Laxminarayan $R$, Bhutta ZA, Duse AG, Jenkins $P$, O'Brien TF, Pablos-Mendez A, Klugman KP: Antimicrobial resistance in developing countries. Part I: recent trends and current status. Lancet Infect Dis 2005, 5:481-493

15. Kalter HD, Gilman RH, Moulton LH, Cullotta AR, Cabrera L, Velapatiño B: Risk factors for antibiotic-resistant Escherichia coli carriage in young children in Peru: community-based cross-sectional prevalence study. AmJTrop Med Hyg 2010, 82:879-888.

16. Seidman JC, Anitha KP, Kanungo R, Bourgeois AL, Coles CL: Risk factors for antibiotic-resistant $E$. coli in children in a rural area. Epidemiol Infect 2009, 137:879-888.

17. Sears HJ, Brownlee I, Uchiyama JK: Persistence of individual strains of Escherichia coli in the intestinal tract of man. J Bacteriol 1950, 59:293-301.

18. Osterblad M, Hakanen A, Manninen R, Leistevuo T, Peltonen R, Meurman O, Huovinen P, Kotilainen P: A between-species comparison of antimicrobial resistance in enterobacteria in fecal flora. Antimicrob Agents Chemother 2000, 44:1479-1484. 
19. Hoa NQ, Ohman A, Lundborg CS, Chuc NT: Drug use and health-seeking behavior for childhood illness in Vietnam-a qualitative study. Health Policy 2007, 82:320-329.

20. Hoa NQ, Larson M, Kim Chuc NT, Eriksson B, Trung NV, Stålsby CL: Antibiotics and paediatric acute respiratory infections in rural Vietnam: health-care providers' knowledge, practical competence and reported practice. Trop Med Int Health 2009, 14:546-555.

21. Hoa NQ, Trung NV, Larsson M, Eriksson B, Phuc HD, Chuc NT, Lundborg CS: Decreased Streptococcus pneumoniae susceptibility to oral antibiotics among children in rural Vietnam: a community study. BMC Infect Dis 2010, 10:85.

22. Nguyen QH, Nguyen TK, Ho DP, Larsson M, Eriksson B, Lundborg CS: Unnecessary antibiotic use for mild acute respiratory infections during 28-day follow-up of 823 children under five in rural Vietnam. Trans $R$ Soc Trop Med Hyg 2011, 105:628-636.

23. Chuc NT, Diwan V: FilaBavi, a demographic surveillance site, an epidemiological field laboratory in Vietnam. Scand J Public Health Suppl 2003, 62:3-7.

24. Larsson M, Kronvall G, Chuc NT, Karlsson I, Lager F, Hanh HD, Tomson G, Falkenberg T: Antibiotic medication and bacterial resistance to antibiotics: a survey of children in a Vietnamese community. Trop Med Int Health 2000, 5:711-721.

25. WHO: WHO collaborating Centre for Drug Statistics Methodology: Anatomical Therapeutic Chemical (ATC) classification index with Defined Daily Doses (DDDs) 2009. Oslo 2008.

26. Hanoi University of Pharmacy: VN Pharmacy, the Vietnamese software for Anatomical Therapeutical Chemical Classification System with Defined Daily Dose (ATC/DDD). Hanoi 2004.

27. Vilchez S, Reyes D, Paniagua M, Bucardo F, Möllby R, Weintraub A: Prevalence of diarrhoeagenic Escherichia coli in children from León, Nicaragua. J Med Microbiol 2009, 58:630-637.

28. Nguyen TV, Le Van P, Le Huy C, Gia KN, Weintraub A: Detection and characterization of diarrheagenic Escherichia coli from young children in Hanoi, Vietnam. J Clin Microbiol 2005, 43:755-760.

29. Clinical and Laboratory Standards Institute: Performance Standards for Antimicrobial Susceptibility Testing Wayne, PA: Twentieth Informational Supplement M100-S17; 2007.

30. Clinical and Laboratory Standards Institute: Performance Standards for Antimicrobial Susceptibility Testing Wayne, PA: Twentieth Informational Supplement M100-S20; 2010.

31. European Committee on Antimicrobial Susceptibility Testing: European antimicrobial breakpoints. Basel 2011 [http://217.70.33.99/Eucast2/ SearchController/search.jsp?action=init].

32. Nguyen TV, Le PV, Le CH, Weintraub A: Antibiotic resistance in diarrheagenic Escherichia coli and Shigella strains isolated from children in Hanoi, Vietnam. Antimicrob Agents Chemother 2005, 49:816-819.

33. Farra A, Skoog G, Wallén L, Kahlmeter G, Kronvall G, Sörberg M: Swebact Study Group: Antibiotic use and Escherichia coli resistance trends for quinolones and cotrimoxazole in Sweden. Scand J Infect Dis 2002, 34:449-455.

34. Lietzau S, Raum E, von Baum H, Marre R, Brenner H: Household contacts were key factor for children's colonization with resistant Escherichia coli in community setting. J Clin Epidemiol 2007, 60:1149-1155.

35. Fornasini M, Reves RR, Murray BE, Morrow AL, Pickering LK: Trimethoprimresistant Escherichia coli in households of children attending day care centers. J Infect Dis 1992, 166:326-330.

36. de Jong A, Bywater R, Butty P, Deroover E, Godinho K, Klein U, Marion H, Simjee S, Smets $K$, Thomas $V$, Vallé $M$, Wheadon A: A pan-European survey of antimicrobial susceptibility towards human-use antimicrobial drugs among zoonotic and commensal enteric bacteria isolated from healthy food-producing animals. J Antimicrob Chemother 2009, 63:733-744.

37. European Committee on Antimicrobial Susceptibility Testing: Ciprofloxacin/ Escherichia coli EUCAST MIC Distribuion. Basel 2011 [http://217.70.33.99/ Eucast2/regShow.jsp?ld=1022].

38. Kronvall G: Normalized resistance interpretation as a tool for establishing epidemiological MIC susceptibility breakpoints. J Clin Microbiol 2010, 48:4445-4452.

39. Stephan R, Ragettli S, Untermann F: Prevalence and characteristics of verotoxin-producing Escherichia coli (VTEC) in stool samples from asymptomatic human carriers working in the meat processing industry in Switzerland. J Appl Microbiol 2000, 88:335-341.
40. Wilson JB, Clarke RC, Renwick SA, Rahn K, Johnson RP, Karmali MA, Lior H, Alves D, Gyles CL, Sandhu KS, McEwen SA, Spika JS: Vero cytotoxigenic Escherichia coli infection in dairy farm families. J Infect Dis 1996, 174:1021-1027.

41. Bailey JK, Pinyon JL, Anantham S, Hall RM: Commensal Escherichia coli of healthy humans: a reservoir for antibiotic-resistance determinants. J Med Microbiol 2010, 59:1331-1339.

\section{Pre-publication history}

The pre-publication history for this paper can be accessed here: http://www.biomedcentral.com/1471-2334/12/92/prepub

doi:10.1186/1471-2334-12-92

Cite this article as: Dyar et al:: High prevalence of antibiotic resistance in commensal Escherichia coli among children in rural Vietnam. BMC Infectious Diseases 2012 12:92.

\section{Submit your next manuscript to BioMed Central and take full advantage of:}

- Convenient online submission

- Thorough peer review

- No space constraints or color figure charges

- Immediate publication on acceptance

- Inclusion in PubMed, CAS, Scopus and Google Scholar

- Research which is freely available for redistribution 